AIRWAY BIOLOGY

\title{
Bronchoalveolar lymphocytosis correlates with human T lymphotropic virus type I (HTLV-I) proviral DNA load in HTLV-I carriers
}

\author{
S Mori, A Mizoguchi, M Kawabata, H Fukunaga, K Usuku, I Maruyama, M Osame
}

Thorax 2005;60:138-143. doi: 10.1136/thx.2004.021667

See end of article for authors' affiliations

Correspondence to:

Dr S Mori, Department of Internal Medicine

Southern Region Hospital, 220 Midori Machi,

Makurazaki City,

Kagoshima 898-0011

Japan; msir@msi.biglobe. ne.jp

Received 20 January 2004 Accepted 7 October 2004

\begin{abstract}
Background: A study was undertaken to investigate the pathogenesis of pulmonary involvement in human T lymphotropic virus type I (HTLV-I) carriers.

Methods: The bronchoalveolar lavage (BAL) cell profile of 30 HTLV-I carriers (15 asymptomatic HTLV-I carriers (AHCs) and 15 symptomatic HTLV-I carriers (SHCs)) with chronic inflammatory diseases of respiratory tract and eight patients with HTLV-I associated myelopathy/tropical spastic paraparesis (HAM/TSP) was investigated. The HTLV-I proviral deoxyribonucleic acid (DNA) load in peripheral blood mononuclear cells (PBMCs) and BAL fluid from HTLV-I carriers was estimated using the quantitative polymerase chain reaction method and the correlation between the lymphocyte number in BAL fluid and the HTLV-I proviral DNA load in PBMCs and BAL fluid was examined.

Results: The percentage of lymphocytes in BAL fluid was increased (>18\%) in 11 of $30 \mathrm{HTLV}-\mathrm{I}$ carriers although there was no significant difference compared with control subjects. In HTLV-I carriers the lymphocyte number in BAL fluid correlated well with the copy number of HTLV-I proviral DNA in PBMCs. In addition, the copy number of HTLV-I proviral DNA in BAL fluid correlated well with the number of lymphocytes (both CD4+ and CD8+ cells) in BAL fluid.

Conclusions: These findings suggest that pulmonary lymphocytosis can occur in a subset of HTLV-I carriers without HAM/TSP and that the increased HTLV-I proviral DNA load may be implicated in the pathogenesis of pulmonary involvement in HTLV-I carriers.
\end{abstract}

$\mathrm{H}$ uman T lymphotropic virus type I (HTLV-I) is a type C retrovirus that is aetiologically associated with adult $\mathrm{T}$ cell leukaemia ${ }^{12}$ and with HTLV-I associated myelopathy/tropical spastic paraparesis (HAM/TSP). ${ }^{3}$ In addition to these diseases, a number of inflammatory disorders have also been described in association with HTLV-I including HTLV-I uveitis, ${ }^{5}$ arthropathy, ${ }^{6}$ and Sjögren's syndrome. ${ }^{7}$ Pulmonary involvement is also associated with HTLV-I-for example, in patients with HAM/TSP and HTLV-I uveitis pulmonary involvement may be characterised by bronchoalveolar lymphocytosis. ${ }^{8-11}$ Furthermore, a few preliminary studies have shown that similar pulmonary involvement is observed in HTLV-I carriers who have not developed HAM/ TSP or HTLV-I uveitis. ${ }^{10} 12$

Many kinds of immunological abnormalities and an increased HTLV-I proviral deoxyribonucleic acid (DNA) load in peripheral blood, cerebrospinal fluid, and bronchoalveolar lavage (BAL) fluid from patients with HAM/TSP ${ }^{13} 14$ and HTLV-I uveitis ${ }^{11}$ have been reported, suggesting that immunological mechanisms related to an increased amount of HTLV-I proviral DNA may be implicated in the pathogenesis of these diseases. However, despite advances in elucidating the pathophysiology of these diseases, much of the information on the pathogenesis is confined to HAM/TSP and HTLV-I uveitis. There is little information available regarding pulmonary involvement and pathophysiology in HTLV-I carriers who have not developed HAM/TSP or HTLV-I uveitis.

To examine the incidence and pathogenesis of pulmonary lymphocytosis in HTLV-I carriers, we have analysed BAL cell profiles in HTLV-I carriers including asymptomatic HTLV-I carriers (AHCs). We also estimated the HTLV-I proviral DNA load in peripheral blood mononuclear cells (PBMCs) and BAL cells from HTLV-I carriers by the quantitative polymerase chain reaction (PCR) method and examined the correlation between the HTLV-I proviral DNA load and pulmonary lymphocytosis.

\section{METHODS}

This study was reviewed and approved by the Kagoshima University Faculty of Medicine Committee on Human Research.

\section{Study subjects}

The study subjects consisted of 30 HTLV-I carriers and eight patients with HAM/TSP consecutively presenting to our department between 1989 and 2000. The 30 HTLV-I carriers consisted of 15 AHCs (three men and 12 women) and 15 symptomatic HTLV-I carriers (SHCs; five men and 10 women) as shown in table 1. There were no significant differences in age between each of the groups and the control subjects. All subjects were seronegative for human immunodeficiency virus (HIV) 1.

To assess the cellular characteristics of BAL fluid in AHCs, the serum anti-HTLV-I antibody was checked in individuals consulting our department for an annual chest radiograph. The anti-HTLV-I antibody was measured by the gelatin particle agglutination method (Fujirebio, Tokyo, Japan). After obtaining informed consent, further examinations including fibreoptic bronchoscopy were performed on HTLV-I seropositive individuals along with careful history taking including occupational history. Individuals who

Abbreviations: AHC, asymptomatic HTLV-I carrier; BAL, bronchoalveolar lavage; HAM/TSP, HTLV-I associated myelopathy/ tropical spastic paraparesis; HTLV-I, human T lymphotropic virus type I; PBMC, peripheral blood mononuclear cell; PCR, polymerase chain reaction; SHC, symptomatic HTLV-I carrier 
Table 1 Clinical background and bronchoalveolar lavage (BAL) findings of HTLV-I carriers and patients with HAM/TSP

\begin{tabular}{|c|c|c|c|c|c|c|c|c|c|c|c|}
\hline \multirow[b]{2}{*}{$\begin{array}{l}\text { Patient no. and clinical } \\
\text { diagnosis/symptoms }\end{array}$} & \multirow[b]{2}{*}{$\begin{array}{l}\text { Age/ } \\
\text { sex }\end{array}$} & \multicolumn{3}{|c|}{ Peripheral blood } & \multicolumn{7}{|c|}{ Bronchoalveolar lavage fluid } \\
\hline & & $\begin{array}{l}\text { WBC } \\
\left(/ \mathrm{mm}^{3}\right)\end{array}$ & $\begin{array}{l}\text { HTLV-I } \\
\text { Ab‡ }(x)\end{array}$ & $\begin{array}{l}\text { Cell count } \\
\left(\times 10^{5} / \mathrm{ml}\right)\end{array}$ & AM (\%) & Ly (\%) & Neu (\%) & Eo (\%) & CD4 (\%) & CD8 (\%) & $\mathrm{CD} 4 / \mathrm{CD} 8$ \\
\hline $1 \mathrm{AHC}$ & $64 / F$ & 4300 & 2048 & 1.4 & 94.3 & 5.0 & 0.8 & 0.0 & ND & ND & ND \\
\hline $2 \mathrm{AHC} \dagger$ & $77 / M$ & 7500 & 2048 & 1.0 & 96.4 & 3.2 & 0.4 & 0.0 & 52.0 & 32.9 & 1.6 \\
\hline $3 \mathrm{AHC}$ & $72 / F$ & 5800 & 256 & 2.0 & 90.2 & 8.3 & 1.3 & 0.2 & 47.1 & 27.3 & 1.7 \\
\hline $4 \mathrm{AHC}$ & $48 / F$ & 2600 & 512 & 0.4 & 86.9 & 12.3 & 0.6 & 0.1 & 48.9 & 29.2 & 1.7 \\
\hline $5 \mathrm{AHC}$ & $57 / \mathrm{F}$ & 6500 & 1024 & 0.7 & 74.9 & 24.6 & 0.5 & 0.0 & 53.5 & 25.0 & 2.1 \\
\hline $6 \mathrm{AHC}$ & $78 / \mathrm{F}$ & 6300 & 8192 & 1.9 & 88.2 & 10.5 & 0.8 & 0.0 & 53.0 & 28.3 & 1.9 \\
\hline $7 \mathrm{AHC}$ & $58 / F$ & 3600 & 8192 & 0.9 & 84.4 & 14.3 & 1.2 & 0.0 & ND & ND & ND \\
\hline $8 \mathrm{AHC}+$ & $64 / M$ & 4300 & 512 & 0.7 & 96.2 & 3.3 & 0.5 & 0.0 & ND & ND & ND \\
\hline $9 \mathrm{AHC}$ & $71 / M$ & 5400 & 4096 & 2.8 & 70.5 & 28.6 & 0.9 & 0.1 & 75.6 & 23.2 & 3.3 \\
\hline $10 \mathrm{AHC}$ & $56 / F$ & 7000 & 128 & 1.0 & 80.5 & 18.7 & 0.6 & 0.1 & 44.5 & 39.5 & 1.1 \\
\hline $11 \mathrm{AHC}$ & $64 / F$ & 4000 & 128 & 1.3 & 89.2 & 9.7 & 0.8 & 0.3 & 58.8 & 22.8 & 2.6 \\
\hline $12 \mathrm{AHC}$ & $55 / \mathrm{F}$ & 3700 & 2048 & 0.6 & 95.3 & 4.0 & 0.3 & 0.5 & ND & ND & ND \\
\hline $13 \mathrm{AHC}$ & $77 / F$ & 4300 & 16384 & 1.5 & 76.1 & 23.4 & 0.4 & 0.1 & 75.3 & 13.4 & 5.6 \\
\hline $14 \mathrm{AHC}$ & $71 / F$ & 5300 & 4096 & 0.6 & 84.3 & 13.5 & 1.6 & 0.5 & 64.6 & 26.9 & 2.4 \\
\hline $15 \mathrm{AHC}$ & $67 / F$ & 4700 & 1024 & 0.8 & 91.5 & 5.5 & 1.2 & 0.0 & 42.8 & 17.1 & 2.5 \\
\hline 16 Chronic cough & $76 / F$ & 5100 & 256 & 1.0 & 93.6 & 5.7 & 0.7 & 0.0 & 37.1 & 34.8 & 1.1 \\
\hline 17 Chronic cough & $67 / F$ & 3900 & 1024 & 0.9 & 68.5 & 30.1 & 1.4 & 0.0 & 71.7 & 25.9 & 2.8 \\
\hline 18 Chronic cough* & $82 / F$ & 7000 & 128 & 1.7 & 95.2 & 4.7 & 0.2 & 0.0 & ND & ND & ND \\
\hline 19 Middle lobe syndrome & $59 / \mathrm{F}$ & 5200 & 4096 & 0.7 & 61.0 & 34.6 & 3.4 & 0.0 & 55.8 & 21.1 & 2.6 \\
\hline 20 SBS & $71 / \mathrm{F}$ & 3400 & 4096 & 0.5 & 92.0 & 7.1 & 0.8 & 0.2 & 48.4 & 31.7 & 1.5 \\
\hline 21 Bronchiectasis & $63 / F$ & 2800 & 2048 & 0.6 & 94.9 & 4.9 & 0.1 & 0.0 & 40.4 & 42.1 & 1.0 \\
\hline 22 Inactive Tbc & $57 / M$ & 3900 & 1024 & 1.3 & 72.7 & 27.3 & 0.0 & 0.0 & 57.1 & 40.5 & 1.4 \\
\hline 23 Inactive Tbct & $73 / M$ & 7000 & 2048 & 3.0 & 94.9 & 4.7 & 0.4 & 0.0 & 60.0 & 30.8 & 2.0 \\
\hline 24 Chronic bronchitis & $47 / M$ & 4700 & 256 & 0.6 & 91.6 & 8.1 & 0.2 & 0.0 & ND & ND & ND \\
\hline 25 Chronic bronchitis* & $57 / M$ & 5200 & 256 & 1.8 & 87.0 & 11.4 & 1.4 & 0.2 & ND & ND & ND \\
\hline 26 Bronchiectasis & $72 / \mathrm{F}$ & 5000 & 512 & 1.9 & 97.4 & 2.6 & 0.0 & 0.0 & ND & ND & ND \\
\hline 27 Bronchiectasis & $68 / F$ & 6000 & 128 & 1.5 & 55.1 & 29.6 & 13.1 & 1.2 & 57.5 & 22.9 & 2.5 \\
\hline 28 SBS & $46 / M$ & 6900 & 2048 & 5.8 & 42.5 & 20.3 & 25.0 & 0.6 & 41.1 & 49.7 & 0.8 \\
\hline 29 Middle lobe syndrome & $66 / F$ & 6300 & 512 & 2.5 & 44.4 & 55.3 & 0.1 & 0.2 & 61.9 & 29.6 & 2.1 \\
\hline 30 SBS & $18 / F$ & 7900 & 4096 & 2.7 & 47.6 & 45.5 & 7.1 & 0.3 & 41.6 & 55.2 & 0.8 \\
\hline $31 \mathrm{HAM} / \mathrm{TSP}$ & $33 / F$ & 4100 & 2048 & 2.0 & 42.7 & 56.8 & 0.2 & 0.2 & 43.1 & 51.5 & 0.8 \\
\hline $32 \mathrm{HAM} / \mathrm{TSP}$ & $50 / \mathrm{F}$ & 4900 & 2048 & 2.3 & 65.6 & 21.0 & 13.4 & 0.0 & 46.4 & 49.2 & 0.9 \\
\hline $33 \mathrm{HAM} / \mathrm{TSP}$ & $54 / \mathrm{F}$ & 2800 & 512 & 1.4 & 63.0 & 36.0 & 1.0 & 0.0 & 69.1 & 28.5 & 2.4 \\
\hline $34 \mathrm{HAM} / \mathrm{TSP}$ & $60 / M$ & 5100 & 512 & 2.4 & 73.4 & 24.5 & 2.1 & 0.0 & 47.1 & 48.2 & 1.0 \\
\hline $35 \mathrm{HAM} / \mathrm{TSP}$ & $65 / F$ & 5200 & 2048 & $\begin{array}{l}2.4 \\
1.7\end{array}$ & 40.8 & 58.9 & 0.3 & 0.0 & 33.1 & 61.0 & 0.5 \\
\hline $36 \mathrm{HAM} / \mathrm{TSP}$ & $59 / \mathrm{F}$ & 4900 & 32768 & 4.0 & 27.0 & 71.9 & 1.1 & 0.0 & 76.2 & 20.4 & 3.7 \\
\hline 37 HAM/TSP & $34 / M$ & 5600 & 8192 & 1.6 & 73.2 & 25.7 & 1.2 & 0.0 & 50.2 & 42.1 & 1.2 \\
\hline 38 HAM/TSP & $50 / \mathrm{M}$ & 6100 & 8192 & 3.9 & 31.2 & 68.3 & 0.0 & 0.5 & 52.0 & 46.9 & 1.1 \\
\hline
\end{tabular}

worked in environments known to cause allergic lung diseases were excluded. After the diagnostic procedure, 15 AHCs were recruited to the study (table 1); the chest radiographic findings were normal in 13 individuals and two had minimal inactive tuberous lesions.

The 15 SHCs (subjects 16-30) were recruited from the outpatient clinic of our department for chronic inflammatory diseases of the respiratory tract (three sinobronchial syndrome, three bronchiectasis, two middle lobe syndrome, and two chronic bronchitis); two had an inactive tuberculous lesion and three (subjects 16-18) complained of a slight cough for 1-3 months during the study. Eight patients with HAM/TSP (three men and five women) had been diagnosed according to the criteria proposed by Osame et al. ${ }^{15}$ Three HTLV-I carriers (subjects 9, 18 and 25) were current smokers, three HTLV-I carriers (subjects 2, 8 and 23) were ex-smokers with intervals ranging from 3 months to 5 years since smoking cessation, and the others had never smoked.

White blood cell counts in peripheral blood were within the normal range in all subjects. The serum anti-HTLV-I antibody titre ranged from 128 to $16384 \times$ in HTLV-I carriers and from 512 to $32768 \times$ in patients with HAM/TSP. The median (range) \% vital capacity of AHCs, SHCs, and patients with HAM/TSP was $104.9 \%$ (77.2-131.8), 85.8\% (75.9-131.3), and $96.7 \%$ (76.7-108.0), respectively, and the \% forced expiratory volume in 1 second in the three groups was $82.2 \%$
(79.3-91.7), 70.7\% (51.6-86.2), and 79.7\% (70.0-88.3\%), respectively. There were no significant differences in pulmonary function between the three groups.

Nine healthy individuals (three men and six women) of median age 53 years, all non-smokers, who were seronegative for HTLV-I acted as controls. They included four healthy volunteers and five healthy individuals undergoing an annual chest radiographic examination. These latter five healthy individuals were finally diagnosed as having a small solitary lung nodule without signs of pulmonary disease $(n=3)$ or minimal inactive tuberculous lesions $(n=2)$. BAL was performed to diagnose the small lung nodule and the cellular characteristics of the BAL fluid from these subjects served as

Table 2 Oligonucleotides for PCR detection of HTLV-I proviral DNA

\begin{tabular}{lll}
\hline Function & Nucleotide sequence $\left(\mathbf{5}^{\prime}\right.$ to $\left.\mathbf{3}^{\prime}\right)$ & Position* $^{*}$ \\
\hline Primer & GGC TCC GTT GTC TGC ATG TA & $7765-7784$ \\
Primer & AAT CAT AGG CGT GCC ATC GG & $8091-8072$ \\
Probe & CCT AAT AAT TCT ACC CGA AGA CTG TTT & \\
& GCC & $7932-7961$ \\
\hline
\end{tabular}

${ }^{*}$ GenBank Accession No. J02029.

PCR, polymerase chain reaction; HTLV-I, human T lymphotropic virus type I. 
control values for this study. The chest radiographic findings of the five healthy volunteers were normal.

\section{Bronchoalveolar lavage}

Informed consent was obtained from all individuals before they underwent BAL which was performed before interventions including corticosteroid administration. Under local anaesthesia with $2 \%$ lidocaine, a fibreoptic bronchoscope was placed in the subsegment of the right middle lobe or lingua and $160 \mathrm{ml}$ sterile saline was infused in four aliquots through the bronchoscope and aspirated by gentle hand suction. The lavage fluid obtained was passed through two sheets of sterile gauze and a $10 \mathrm{ml}$ aliquot was centrifuged at $400 \mathrm{~g}$ for 10 minutes, stained with Wright-Giemsa stain, and the cell differentials were determined (at least 500 cells were counted). The lavage fluid was then washed twice and the total number of cells counted.

An aliquot of BAL cells was used for identification of $\mathrm{T}$ lymphocyte subsets. The cells were washed twice with phosphate buffered saline and incubated with an optimal concentration of fluorescence conjugated monoclonal antibodies (OKT4 (CD4), OKT8 (CD8); Ortho Diagnostics, Raritan, NJ, USA). The cells were then analysed for surface fluorescence using flow cytometry (FCMID, Nihon Bunko, Tokyo, Japan).

\section{Isolation of peripheral blood mononuclear cells (PBMCs)}

The PBMCs were isolated from $30 \mathrm{ml}$ heparinised peripheral blood by Ficoll-Hypaque density gradient centrifugation (Pharmatica, Uppsala, Sweden). Blood samples were obtained before performing BAL in all subjects. These samples were stored in liquid nitrogen until use.

\section{Quantitative PCR of PBMCs and BAL cells}

Quantitative PCR assay was performed as previously described. ${ }^{16}$ The amount of HTLV-I proviral DNA was calculated using the following formula: copy number of HTLV-I $(\mathrm{pX})$ per $10^{4}$ PBMCs and per $10^{4}$ BAL cells $=[($ copy number of $\mathrm{pX}) /\left(\right.$ copy number of $\beta$-actin/2)] $\times 10^{4}$

\section{Detection of HTLV-I proviral DNA from BAL cells by PCR}

To examine the presence of HTLV-I proviral DNA in BAL cells, isolated BAL cells from 10 initial AHCs (nos 1-9 and 11) were analysed. As negative and positive controls, BAL cells and HTLV-I infected TCL-Kan cells ${ }^{17}$ from HTLV-I seronegative controls were also assayed. $1 \mu \mathrm{g}$ of DNA extracted from BAL cells was used for the PCR. The amplification reaction of PCR
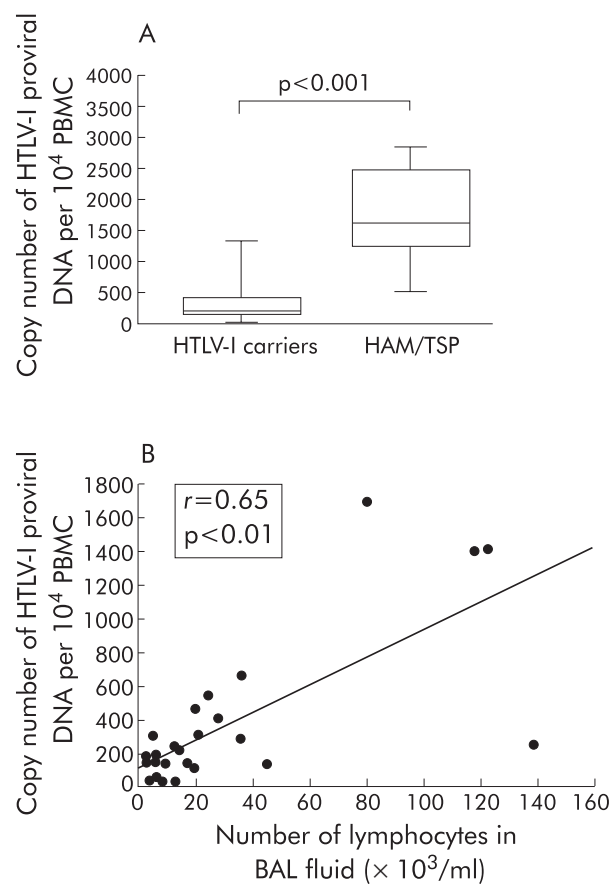

Figure 1 (A) Copy number of HTLV-I proviral DNA per $10^{4}$ PBMCs in HTLV-I carriers and patients with HAM/TSP. The whisker box plots represent the 25-75th percentile of results inside the box, the median is shown by the horizontal bar across the box, and whiskers on the box represent the 10-90th percentiles. (B) Correlation between the number of lymphocytes in bronchoalveolar lavage (BAL) fluid and the copy number of HTLV-I proviral DNA per $10^{4}$ PBMCs in HTLV-I carriers. HTLVI, human T lymphotropic virus type I; PBMCs, peripheral blood mononuclear cells; HAM/TSP $=\mathrm{HTLV}$-I associated myelopathy/tropical spastic paraparesis.

was performed for 35 cycles and consisted of denaturation at $94^{\circ} \mathrm{C}$ for 1 minute, annealing at $65^{\circ} \mathrm{C}$ for 2 minutes, and primer extension at $72^{\circ} \mathrm{C}$ for 3 minutes. $10 \mu \mathrm{l}$ of the amplified products was blotted onto a nylon membrane and hybridised with a biotin labelled probe for HTLV-I pX. After incubation with streptavidin-alkaline phosphate conjugate, disodium 3(4-methoxyspirol [1,2-dioxetane-3-2'-tricyclo-[3.3.1.1.3.7] decan]-4-yl)phenyl phosphate (AMPPD) ${ }^{18}$ (Southern Light Kit, Troix) was added to the blot to a final concentration of $0.25 \mathrm{mM}$ and the immersed blot was then slowly agitated for 5 minutes. Finally, the chemiluminescent signal was detected by exposing the radiographic film.

Table 3 Bronchoalveolar lavage findings in HTLV-I carriers and HAM/TSP patients

\begin{tabular}{lllllllll}
\hline Subjects & $\begin{array}{l}\text { Cell count } \\
(\times \mathbf{1 0} / \mathbf{m l})\end{array}$ & AM (\%) & Ly $(\%)$ & Neu $(\%)$ & Eo $(\%)$ & CD4+ cells $(\%)$ & CD8+ cells (\%) & CD4/CD8 \\
\hline HTLV-I carriers & $1.2^{* *}$ & 87.6 & 11.0 & 0.8 & 0.0 & 53.3 & 28.8 & 1.9 \\
N=30 (22)† & $(0.4-5.8)$ & $(42.5-97.4)$ & $(2.6-55.3)$ & $(0.0-25.0)$ & $(0.0-1.2)$ & $(37.1-75.6)$ & $(13.4-55.2)$ & $(0.8-5.6)$ \\
AHCs & $1.0^{*}$ & 88.2 & 10.5 & 0.8 & 0.1 & 53.0 & 26.9 & $2.1^{*}$ \\
$\mathrm{~N}=15(11) \dagger$ & $(0.4-2.8)$ & $(70.5-96.4)$ & $(3.2-28.6)$ & $(0.3-1.6)$ & $(0.0-0.5)$ & $(42.8-75.6)$ & $(13.4-39.5)$ & $(1.1-5.6)$ \\
SHCs & $1.5^{* *}$ & 87.0 & 11.4 & 0.7 & 0.0 & 55.8 & 31.7 & 1.5 \\
$\mathrm{~N}=15(11) \dagger$ & $(0.5-5.8)$ & $(42.5-97.4)$ & $(2.6-55.3)$ & $(0.0-25.0)$ & $(0.0-1.2)$ & $(37.1-71.7)$ & $(21.1-55.2)$ & $(0.8-2.8)$ \\
HAM/TSP & $2.2^{* *}$ & $52.9^{* *}$ & $46.4^{* *}$ & 1.1 & 0.0 & 48.7 & $47.6^{*}$ & 1.0 \\
$\mathrm{~N}=8$ & $(1.4-4.0)$ & $(27.0-73.4)$ & $(21.0-71.9)$ & $(0.0-13.4)$ & $(0.0-0.5)$ & $(33.1-76.2)$ & $(20.4-61.0)$ & $(0.5-3.7)$ \\
Controls & 0.6 & 91.2 & 8.4 & 0.6 & 0.1 & 48.7 & 31.4 & 1.5 \\
$\mathrm{~N}=9$ & $(0.3-1.0)$ & $(87.9-95.8)$ & $(3.8-10.5)$ & $(0.2-1.3)$ & $(0.0-0.4)$ & $(33.4-59.5)$ & $(22.7-45.1)$ & $(0.9-2.1)$ \\
\hline
\end{tabular}

Data are shown as median (range).

N, number of subjects; AM, alveolar macrophage; Ly, lymphocyte; Neu, neutrophil; Eo, eosinophil; HTLV-I, human T lymphotropic virus type I; AHCs, asymptomatic HTLV-I carriers; SHCs, symptomatic HTLV-I carriers with chronic inflammatory diseases of respiratory tract; HAM/TSP, HTLV-I-associated myelopathy/tropical spastic paraparesis.

${ }^{*} \mathrm{p}<0.05,{ }^{* *} \mathrm{p}<0.01$ compared with control subjects.

†The cell differential in BAL fluid was determined in 30 HTLV-I carriers (15 AHCs and 15 SHCs) and T lymphocyte subsets were determined in 22 HTLV-I carriers (11 AHCs and 11 SHCs). 
Table 4 Quantification of HTLV-I proviral DNA in PBMCs and BAL fluid from HTLV-I carriers and HAM/TSP patients

\begin{tabular}{|c|c|c|c|c|c|c|}
\hline \multirow[b]{2}{*}{ Subjects } & \multicolumn{3}{|c|}{ PBMCs } & \multicolumn{3}{|c|}{ BAL fluid } \\
\hline & $\mathbf{N}$ & Median & Range & $\mathbf{N}$ & Median & Range \\
\hline HTLV-I carriers & 26 & 199 & ND-1704 & 14 & 126 & $22-1268$ \\
\hline $\mathrm{AHCs}$ & 11 & 138 & ND-1704 & 3 & 75 & $70-132$ \\
\hline SHCs & 15 & 232 & $30-1390$ & 11 & 141 & $22-1268$ \\
\hline HAM/TSP & 8 & $1611^{*}$ & $261-2857$ & 8 & $601^{* *}$ & $294-3495$ \\
\hline
\end{tabular}

HTLV-I copy number per $10^{4}$ PBMCs and per $10^{4}$ BAL cells are presented.

HTLV-I, human T lymphotropic virus type I; AHCs, asymptomatic HTLV-I carriers; SHCs, symptomatic HTLV-I carriers with chronic inflammatory diseases of respiratory tract; HAM/TSP, HTLV-I associated myelopathy/tropical spastic paraparesis; PBMCs, peripheral blood mononuclear cells; BAL, bronchoalveolar lavage; N, number of subjects; ND, not detected.

${ }^{*} \mathrm{p}<0.01$ compared with HTLV-I carriers, AHCs and SHCs; ${ }^{* *} \mathrm{p}<0.01$ compared with HTLV-I carriers and SHCs.

The location and sequences of the primers and probe are summarised in table 2.

\section{Statistical analysis}

All values are shown as median (range). Statistical analysis was performed using the Mann-Whitney $U$ test and Spearman rank correlation. $p$ values of $<0.05$ were considered significant.

\section{RESULTS}

\section{Cellular characteristics and T lymphocyte subset of BAL fluid}

The recovery ratios of BAL fluid in HTLV-I carriers, AHCs, SHCs, and patients with HAM/TSP did not differ significantly from those of control subjects (data not shown). As shown in table 3, the BAL fluid cell count was increased in HTLV-I carriers, AHCs, SHCs, and patients with HAM/TSP compared with control subjects. The differential cell count showed an increased percentage of lymphocytes and a decreased percentage of macrophages in BAL fluid from patients with HAM/TSP compared with control subjects. The percentage of lymphocytes in BAL fluid was increased $(>18 \%)$ in four AHCs and seven SHCs but there was no significant difference from that in control subjects.

Analysis of T lymphocyte subsets in BAL fluid showed an increased percentage of CD8+ cells in patients with HAM/TSP and an increased ratio of CD4/CD8 in AHCs.

\section{HTLV-I proviral DNA in PBMCs and correlation with lymphocytes in BAL fluid}

The copy number of HTLV-I proviral DNA in PBMCs was determined in 26 HTLV-I carriers ( 11 AHCs and 15 SHCs) and eight patients with HAM/TSP. As shown in table 4 and fig $1 \mathrm{~A}$, the copy number of HTLV-I proviral DNA per $10^{4}$ PBMCs was significantly increased in patients with HAM/TSP compared with those of HTLV-I carriers $(p<0.001)$, AHCs $(p<0.01)$, and SHCs $(p<0.01)$. There was no significant difference in the copy number of HTLV-I proviral DNA of PBMCs between AHCs and SHCs.

The relationship between the HTLV-I proviral load in PBMCs and the lymphocyte number in BAL fluid was examined in 26 HTLV-I carriers. As shown in fig 1B, the number of lymphocytes in BAL fluid correlated well with the copy number of HTLV-I proviral DNA in PBMCs of HTLV-I carriers $(r=0.65, \mathrm{p}<0.05)$.

HTLV-I proviral DNA in BAL fluid and correlation with lymphocytes and T lymphocyte subsets in BAL fluid

HTLV-I proviral DNA was detected by PCR in BAL cells from all 10 AHCs examined and was not detected in BAL cells from HTLV-I seronegative controls.

The copy number of HTLV-I proviral DNA in BAL fluid was determined in 14 HTLV-I carriers (three AHCs and 11 SHCs) and in eight patients with HAM/TSP. As shown in table 4, the copy number of HTLV-I proviral DNA per $10^{4}$ BAL cells was significantly increased in patients with HAM/TSP compared with those of HTLV-I carriers $(p<0.001)$ and SHCs $(\mathrm{p}<0.01)$.

The correlation between HTLV-I proviral DNA load, lymphocyte number, and $\mathrm{T}$ cell subsets in BAL fluid was examined in 14 HTLV-I carriers and 10 HTLV-I carriers. The copy number of HTLV-I proviral DNA in BAL fluid correlated well with the number of lymphocytes in BAL fluid from HTLV-I carriers $(r=0.58, \mathrm{p}<0.05$, fig $2 \mathrm{~A})$, CD4+ cells $(r=0.77, \mathrm{p}<0.05$, fig $2 \mathrm{~B})$, and CD8+ cells $(r=0.83, \mathrm{p}<0.05$, fig $2 \mathrm{C})$.
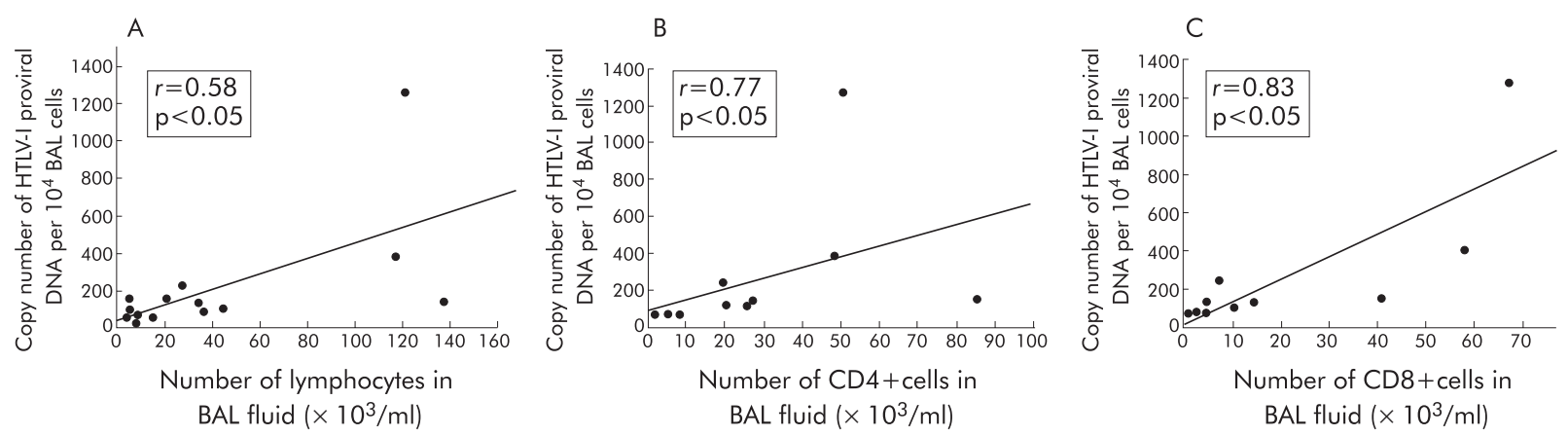

Figure 2 Correlation between (A) the number of lymphocytes in bronchoalveolar lavage (BAL) fluid and the copy number of HTLV-I proviral DNA per $10^{4}$ BAL cells from HTLV-I carriers; (B) the number of CD4+ cells in BAL fluid and the copy number of HTLV-I proviral DNA per $10^{4}$ BAL cells from HTLV-I carriers; and (C) the number of CD8+ cells in BAL fluid and the copy number of HTLV-I proviral DNA per $10^{4}$ BAL cells from HTLV-I carriers. Statistical analyses were performed using Spearman rank correlation. HTLV-I, human T lymphotropic virus type I. 


\section{Follow up of asymptomatic HTLV-I carriers with bronchoalveolar lymphocytosis}

Three AHCs (subjects 5, 10 and 13) with bronchoalveolar lymphocytosis (>18\% lymphocytes in BAL fluid) were available for follow up evaluation of clinical and radiographic variables for 5-10 years. A further individual (subject 9) dropped out l year after the study. None of these four individuals showed overt respiratory illness and chest radiographic findings remained normal during the follow up period. They did not develop adult T cell leukaemia, HAM/ TSP, or other HTLV-I associated disorders during this time.

\section{DISCUSSION}

The major findings of this study are: (1) bronchoalveolar lymphocytosis (>18\% lymphocytes in BAL fluid) was observed in 11 of 30 HTLV-I carriers without HAM/TSP or HTLV-I uveitis $(36.7 \%)$, although there was no significant difference between HTLV-I carriers and control subjects; (2) the number of lymphocytes in the BAL fluid of HTLV-I carriers was significantly correlated with the HTLV-I proviral DNA load in PBMCs; and (3) the HTLV-I proviral DNA load in the BAL fluid was significantly correlated with the number of lymphocytes, CD4+ cells and CD8+ cells in the BAL fluid of HTLV-I carriers.

Recent studies have indicated that immunological dysfunction related to the increased HTLV-I proviral load may be involved in the pathogenesis of HAM/TSP and HTLV-I uveitis. ${ }^{13}{ }^{16}{ }^{19-23}$ However, some studies have shown that these immunological and virological findings are also present in some HTLV-I carriers including relatives of subjects with HAM/TSP and AHCs who have not developed HAM/TSP or HTLV-I uveitis..$^{13} 1620$ The genetic background may be implicated in the HTLV-I proviral load and immunological dysfunction in HTLV-I carriers. ${ }^{21}{ }^{24}$ These reports suggest that HTLV-I carriers consist of groups of individuals of different genetic backgrounds with various amounts of HTLV-I proviral DNA in PBMCs. Our results showed that the HTLV-I proviral load is high in a subset of HTLV-I carriers without HAM/TSP or HTLV-I uveitis and that the increased HTLV-I proviral load correlates well with bronchoalveolar lymphocytosis in HTLV-I carriers. The present findings, together with those of previous studies, suggest that an increased HTLV-I proviral load may lead to certain systemic conditions including bronchoalveolar lymphocytosis in HTLV-I carriers.

In addition to the genetic background, direct or indirect mechanisms induced by inflammatory conditions may have influenced the HTLV-I proviral load in PBMCs of some SHCs with chronic inflammatory diseases of the respiratory tract in this study, as occurs in HIV-1 infection. ${ }^{25}$

The HTLV-I proviral load in BAL fluid appeared to be related to the proportion of lymphocytes in the BAL fluid of HTLV-I carriers, as reported previously. ${ }^{26}$ Interestingly, the HTLV-I proviral load in the BAL fluid correlated with the number of CD8+ cells as well as with the number of CD4+ cells in HTLV-I carriers, even though CD4+ cells are thought to be preferentially infected by HTLV-I. ${ }^{27}$ Our findings may be consistent with more recent observations of the tropism of HTLV-I to CD8+ lymphocytes. ${ }^{28}{ }^{29}$ Further investigations are needed to determine which $\mathrm{T}$ cell subsets are predominantly infected with HTLV-I in the lungs of HTLV-I carriers.

A few studies have described some AHCs with bronchoalveolar lymphocytosis who did not develop HAM/TSP and HTLV-I uveitis. ${ }^{30} 31$ In the present study pulmonary involvement was subclinical in AHCs with bronchoalveolar lymphocytosis, similar to the findings of these previous studies. Furthermore, follow up studies suggested that the clinical development of bronchoalveolar lymphocytosis may be delayed in HTLV-l carriers.
HTLV-I infected lymphocyte(s) commonly exist in the lower respiratory tract of HTLV-I seropositive individuals, as shown in the PCR study of BAL cells. This suggests that factors other than the presence of HTLV-I in the lung-such as a systemic increase in the HTLV-I proviral load, as found in this study-may be necessary for excessive accumulation of lymphocytes in the lung. The mechanisms by which an increased HTLV-I proviral load affects pulmonary involvement in HTLV-I carriers remains to be fully clarified. One possible mechanism is that the increased number of HTLV-I infected cells enhances the probability that infected cells will enter the target organs, ${ }^{31}{ }^{32}$ resulting in a local inflammatory response. However, the frequency of HTLV-I specific cytotoxic T lymphocytes $22{ }^{23}{ }^{33}$ related to the increased amount of the virus might be involved in the pathogenesis, as has been shown in lung disorders of patients with HIV infection. ${ }^{25} 34$

In conclusion, we have shown that pulmonary lymphocytic infiltration can occur in a subset of HTLV-I carriers who have not developed HAM/TSP or HTLV-I uveitis. This pulmonary involvement may be associated with an increased amount of HTLV-I proviral DNA in peripheral blood.

\section{Authors' affiliations}

S Mori, M Kawabata, K Usuku, M Osame, Third Department of Internal Medicine, Kagoshima University School of Medicine, 8-35-1 Sakuragaoka, Kagoshima 890-8520, Japan

A Mizoguchi, H Fukunaga, Department of Respiratory Medicine, Minamikyusyu National, Sanatorium, 1882 Kida, Kajikicho, Kagoshima 899-5241, Japan

I Maruyama, Department of Laboratory Medicine, Kagoshima University School of Medicine, 8-35-1 Sakuragaoka, Kagoshima 8908520, Japan

\section{REFERENCES}

1 Poiesz BJ, Ruscetti FW, Gazdar AF, et al. Detection and isolation of type C retrovirus particles from fresh and cultured lymphocytes of a patient with cutaneous T-cell lymphoma. Proc Natl Acad Sci USA 1980;77:7415-9.

2 Hinuma Y, Nagata K, Hanaoka M, et al. Adult T cell leukemia antigen in an ATL cell line and detection of antibodies to the antigen in human sera. Proc Natl Acad Sci USA 1981;78:6476-80.

3 Gassain A, Barin F, Vernant JC, et al. Antibodies to human T lymphotropic virus type I in patients with tropical spastic paraparesis. Lancet 1985;2:407-10.

4 Osame M, Usuku K, Izumo S, et al. HTLV-I-associated myelopathy, a new clinical entity. Lancet 1986;1:1031-2.

5 Mochizuki M, Watanabe T, Yamaguchi K, et al. Uveitis associated with human T-cell lymphotropic virus type I. Am J Ophthalmol 1992;114:123-9.

6 Nishioka K, Maruyama I, Sato K, et al. Chronic inflammatory arthropathy associated with HTLV-I. Lancet 1989;1:441-2.

7 Vernant JC, Buisson G, Magdeleine J, et al. T-lymphocyte alveolitis, tropical spastic paraparesis and Sjögren's syndrome. Lancet 1988;1:177.

8 Sugimoto $M$, Nakashima $H$, Watanabe $S$, et al. T-lymphocyte alveolitis in HTLV-I-associated myelopathy. Lancet 1987;2:1220.

9 Couderc LJ, Caubarrere I, Venet A, et al. Bronchoalveolar lymphocytosis in patients with tropical spastic paraparesis associated with human T-cell ymphotropic virus type-I (HTLV-I): clinical, immunologic and cytologic studies. Ann Intern Med 1988; 109:625-8.

10 Maruyama I, Tihara J, Sakasita I, et al. HTLV-I-associated bronchopneumonopathy: a new clinical entity? Am Rev Respir Dis 1988;137(Suppl):46.

11 Sugimoto M, Mita S, Tokunaga M, et al. Pulmonary involvement in human Tcell lymphotropic virus type-I uveitis: T-lymphocytosis and high proviral DNA load in bronchoalveolar lavage fluid. Eur Respir J 1993;6:938-43.

12 Sugimoto $M$, Kitaichi M, Ikeda A, et al. Chronic bronchioloalveolitis associated with human T-cell lymphotropic virus type I infection. Curr Opin Pulm Med 1998;4:98-102.

13 Kubota R, Osame M, Jacobson S. Retrovirus: human T-cell lymphotropic virus type l-associated diseases and immune dysfunction. In: Cunningham MW, Fujinami RS, eds. Effect of microbes on the immune system. Philadelphia: Lippincott Williams \& Wilkins, 2000:349-71.

14 Sugimoto $M$, Nakashima $H$, Matsumoto $M$, et al. Pulmonary involvement in patients with HTLV-I-associated myelopathy: increased soluble IL-2 receptors in bronchoalveolar lavage fluid. Am Rev Respir Dis 1989;139:1329-35.

15 Osame M, Matsumoto M, Usuku K, et al. Chronic progressive myelopathy associated with elevated antibodies to human T-lymphotropic virus type I and adult T-cell leukaemia like cells. Ann Neurol 1987;21:117-22.

16 Nagai M, Usuku K, Matsumoto W, et al. Analysis of HTLV-I proviral load in 202 HAM/TSP patients and 243 asymptomatic HTLV-I carriers: high proviral load strongly predisposes to HAM/TSP. J Neurovirol 1998;4:586-93. 
17 Kannagi M, Sugamura K, Sato H, et al. Establishment of human cytotoxic cell lines specific for human adult T-cell leukemia virus-bearing cells. J immunol 1983;130:2942-6.

18 Bronstein L, Voyta JC, Lazzari KG, et al. Rapid and sensitive detection of DNA in Southern blots with chemiluminescence. Bio Techniques 1990:8:310-4.

19 Kira J, Koyanagi Y, Yamada T, et al. Increased HTLV-I proviral DNA in HTLVI-associated myelopathy: a quantitative polymerase chain reaction study. Ann Neurol 1991;29:194-201.

20 Yoshida M, Osame M, Kawai H, et al. Increased replication of HTLV-I in HTLV-I-associated myelopathy. Ann Neurol 1989;26:331-5.

21 Usuku K, Sonoda S, Osame M, et al. HLA haplotype-linked high immune responsiveness against HTLV-I in HTLV-I-associated myelopathy: comparison with adult T-cell leukemia/lymphoma. Ann Neurol 1988;23:143-50.

22 Jacobson S, Shida H, McFarlin DE, et al. Circulating CD8+ cytotoxic T lymphocytes specific for HTLV-I $\mathrm{DX}$ in patients with HTLV-I-associated neurological disease. Nature 1990;348:245-8.

23 Elovaara I, Koenig S, Brewah Y, et al. High human T cell lymphotropic virus type I (HTLV-I)-specific precursor cytotoxic T lymphocyte frequencies in patients with HTLV-I-associated neurological disease. J Exp Med 1993;177:1567-73.

24 Jeffery KJM, Usuku K, Hall SE, et al. HLA alleles determine human Tlymphotropic virus-I (HTLV-I) proviral load and the risk of HTLV-I-associated myelopathy. Proc Natl Acad Sci USA 1999;96:3848-53.

25 Agostini C, Trentin L, Zambello R, et al. HIV-I and the lung. Am Rev Respir Dis 1993; 147:1038-49.
26 Desgranges $C$, Bechet JM, Couderc $\sqcup$, et al. Detection of HTLV-I DNA by polymerase chain reaction in alveolar lymphocytes of patients with tropical spastic paraparesis. J Infect Dis 1989;160:162-3.

27 Richardson JH, Edwarpds AJ, Cruickshank JK, et al. In vivo cellular tropism of human T-cell leukemia virus type I. J Virol 1990:64:5682-7.

28 Hanon E, Stinchcombe JC, Saito M, et al. Fratricide among CD8+ T lymphocytes naturally infected with human $T$ cell lymphotropic virus type I. Immunity 2000; 13:657-64.

29 Nagai $M$, Brennan MB, Sakai JA, et al. CD8+ T cells are an in vivo reservoir for human T-cell lymphotropic virus type I. Blood 2001;98:1858-61.

30 Mukae H, Kohno S, Morikawa N, et al. Increase in T-cell bearing CD25 in bronchoalveolar lavage fluid from HAM/TSP patients and HTLV-I carriers. Microbiol Immunol 1994;38:55-62.

31 Seki M, Higashiyama Y, Kadota J, et al. Elevated levels of soluble adhesion molecules in sera and BAL fluid of individuals infected with human T-cell lymphotropic virus type I. Chest 2000;1 18:1754-61.

32 Ichinose K, Nakamura T, Kawakami A, et al. Increased adherence of T cells to human endotherial cells in patients with human T-cell lymphotropic virus type I-associated myelopathy. Arch Neurol 1992:49:74-6.

33 Nagai M, Yamano Y, Brennan MB, et al. Increased HTLV-I proviral load and preferential expansion of HTLV-I tax specific CD8+ T cells in cerebrospinal fluid from patients with HAM/TSP. Ann Neurol 2001;50:807-12.

34 Plata F, Autran B, Martins L, et al. AIDS virus-specific cytotoxic T lymphocytes in lung disorders. Nature 1987;328:348-51.

\section{LUNG ALERT}

Some asthma genotypes may not respond to $\beta_{2}$ agonists

$\Delta$ Israel E, Chinchilli VM, Ford JG, et al. Use of regularly scheduled albuterol treatment in asthma: genotype-stratified, randomised, placebo-controlled cross-over trial. Lancet 2004;364:1505-12

$\mathrm{T}$

his was a prospective crossover trial comparing the use of salbutamol with placebo in 78

mild asthmatics (diagnosed by chest physician, only using inhaled $\beta$ agonist $<56$ puffs/

week, $\mathrm{FEV}_{1}>70 \%$ ) aged $18-55$ years. $50 \%$ had a genetic polymorphism resulting in homozygosity for arginine (Arg/Arg) at amino acid residue number 16 of the $\beta_{2}$ agonist receptor instead of glycine (Gly/Gly), as in the other half. Each patient was matched with a patient from the other group by $\mathrm{FEV}_{1}$.

Following a 6 week run in period using a placebo metered dose inhaler (two puffs qds; rescue medication ipratropium inhaler), each pair was randomised to receive either active salbutamol $(90 \mu \mathrm{g}$ ) or placebo (two puffs qds) for 16 weeks followed by an 8 week run out period using placebo and then crossed over. In the Gly/Gly group there was no change in pre-inhaler morning peak expiratory flow rate (PEFR) with placebo but an increase in PEFR with salbutamol producing a difference of $14 \mathrm{l} / \mathrm{min}(\mathrm{p}<0.05)$. In the Arg/Arg group the reverse occurred with a difference of $-10 \mathrm{l} / \mathrm{min}(\mathrm{p}<0.05)$. This group also needed to use their ipratropium inhaler more, which did produce an increase in PEFR. Similar results were seen in $\mathrm{FEV}_{1}$, symptom scores, and rescue inhaler use.

It appears that Gly/Gly patients respond to salbutamol while those with Arg/Arg seem to get better when salbutamol is withdrawn. It may be that the latter group actually responds to ipratropium. A longer treatment trial is needed with more patients with more severe asthma and with other genetic polymorphisms, using other $\beta_{2}$ agonists, to determine if reliever strategies excluding salbutamol are more suitable for Arg/Arg patients.

N Batsford

Specialist Registrar, Castle Hill Hospital, Hull, Yorkshire, UK; N.Batsford@doctors.org 